\title{
KARAKTERIZACIJA VELIČINA ZAVISNIH OD VREMENA PRIMENOM SREDNJIH VREDNOSTI
}

\section{CHARACTERIZATION OF TIME-DEPENDENT VALUES USING THE MEAN VALUES}

\section{Oblast - PRIMENJENA MATEMATIKA}

Kratak sadržaj - U ovom radu ilustrovana je metoda za određivanje efektivne vrednosti vremenski zavisne veličine.

Ključne reči: aritmetička sredina, standardna devijacija, veličine zavisne od vremena

Abstract - In this paper, one method of determining effective value of time-dependent value is presented.

Keywords: arithmetic mean, standard deviation, time dependent values

\section{UVOD}

Rezultati prikazani u ovom delu mogu se naći u $[1,2]$. Teorija verovatnoće je matematička disciplina u okviru koje se izučavaju eksperimenti čiji ishod nije jednoznačno određen. Osnovna podela eksperimenata je na determinističke i verovatnosne (stohastičke).

Osnovni pojam teorije verovatnoće je neprazan skup $\Omega$ koji predstavlja skup svih mogućih ishoda posmatranog eksperimenta. Slučajni događaj je bilo koji podskup skupa $\Omega$.

Za definisanje prostora verovatnoće potrebno je posmatrati nepraznu familiju $\mathcal{F}$ podskupova skupa $\Omega$ koja zadovoljava sledeće osobine:

- $\operatorname{skup} \Omega$ pripada familiji $\mathcal{F}$,

- ako se skup $A$ nalazi u posmatranoj familiji $\mathcal{F}$, onda se u njoj nalazi i komplement skupa $A$,

- familija $\mathcal{F}$ je zatvorena u odnosu na prebrojive unije.

Neprazna familija podskupova skupa $\Omega$ koja zadovoljava navedene osobine naziva se $\sigma$-algebra podskupova nad $\Omega$. Verovatnoća je funkcija $P: \mathcal{F} \rightarrow[0,1]$ koja zadovoljava osobine

- normiranosti,

- $\sigma$-aditivnosti.

Uređena trojka $(\Omega, \mathcal{F}, P)$ naziva se prostor verovatnoće. Preslikavanje kojim se skup mogućih ishoda nekog verovatnosnog eksperimenta preslikava na realnu osu je slučajna promenljiva.

Funkcija raspodele $F_{X}: \mathbb{R} \rightarrow[0,1]$ slučajne promenljive $X$ definisana je sa

$$
F_{X}(x)=P\{\omega \in \Omega: X(\omega) \leq x\} .
$$

\section{NAPOMENA:}

Ovaj rad proistekao je iz master rada čiji mentor je bila dr Slavica Medić, docent.
Osnovna podela slučajnih promenljivih jeste na slučajne promenljive:

- diskretnog tipa,

- apsolutno neprekidnog tipa i

- mešovitog tipa.

Brojne karakteristike slučajne promenljive su vrednosti kojima reprezentujemo slučajnu promenljivu i koje nam služe za jednostavnije sagledavanje njenih osnovnih karakteristika. Postoje dve osnovne grupe brojnih karakteristika slučajne promenljive. Prvu grupu čine brojne karakteristike koje karakterišu centar grupisanja vrednosti slučajne promenljive, dok drugu grupu čine brojne karakteristike koje karakterišu stepen rasipanja slučajne promenljive u odnosu na njen centar.

U brojne karakteristike koje karakterišu centar grupisanja vrednosti slučajne promenljive spadaju matematičko očekivanje, medijana i modus.

Matematičko očekivanje slučajne promenljive $X$ diskretnog tipa, u oznaci $E(X)$, je

$$
E(X)=\sum_{i} x_{i} p\left(x_{i}\right),
$$

pod uslovom da red na desnoj strani prethodne jednakosti apsolutno konvergira,

Matematičko očekivanje $E(X)$ slučajne promenljive $X$ apsolutno neprekidnog tipa je

$$
E(X)=\int_{-\infty}^{\infty} x \varphi_{X}(x) d x,
$$

pod uslovom da integral na desnoj strani prethodne jednakosti apsolutno konvergira.

Disperzija, u oznaci $D(X)$, je brojna karakteristika koja karakteriše rasutost slučajne promenljive i definisana je sa

$$
D(X)=E\left((X-E(X))^{2}\right) .
$$

Koren disperzije, $\sqrt{D(X)}$, naziva se standardna devijacija ili standardno odstupanje slučajne promenljive $X$.

Neka je $(\Omega, \mathcal{F}, P)$ prostor verovatnoće i neka su $X_{i}: \Omega \rightarrow$ $\mathbb{R}, \quad i \in\{1,2, \ldots, n\}$ slučajne promenljive (nad istim prostorom verovatnoće). Uređena $n$-torka $\left(X_{1}, X_{2}, \ldots, X_{n}\right)$ se naziva $n$-dimenzionalna slučajna promenljiva ili slučajni vektor. $n$-dimenzionalna slučajna promenljiva $\left(X_{1}, X_{2}, \ldots, X_{n}\right)$ svakom elementu $\omega \in \Omega$ dodeljuje element iz $\mathbb{R}^{n}$, tj.

$$
\left(X_{1}, X_{2}, \ldots, X_{n}\right)(\omega)=\left(X_{1}(\omega), X_{2}(\omega), \ldots, X_{n}(\omega)\right) .
$$


Funkcija raspodele $n$-dimenzionalne slučajne promenljive definiše se slično kao i funkcija raspodele jednodimenzionalne slučajne promenljive, $\mathrm{t} \mathrm{j}$.

$F_{X_{1}, X_{2}, \ldots, X_{N}}\left(x_{1}, x_{2}, \ldots, x_{n}\right)$

$=P\left\{\omega \in \Omega: X_{1}(\omega) \leq x_{1}, \ldots, X_{n}(\omega) \leq x_{n}\right\}$.

Skup elemenata koji se ispituje ili o kome se prikupljaju potrebne informacije naziva se populacija ili osnovni skup. Na populaciji se ispituje neka karakteristika koja se naziva obeležje. U ovom radu se posmatraju samo numerička obeležja, tj. svakom elementu populacije se dodeljuje određena brojna (numerička) vrednost. U terminologiji teorije verovatnoće populacija je skup $\Omega$, a obeležje je slučajna promenljiva.

Često u praksi nije moguće dobiti informacije o celoj populaciji koja se posmatra (velika populacija, veliki troškovi, potrebno puno vremena,...), pa se iz populacije bira jedan njen deo koji se izučava. Taj deo se naziva uzorak. Treba primetiti da je broj elemenata u uzorku uvek konačan (za razliku od populacije koja može biti i beskonačna) i da se on naziva obim uzorka i označava sa $n$. Ako je i broj elemenata u populaciji konačan on se označava sa $N$.

Osnovna ideja matematičke statistike je da se istraživanja sprovedu na uzorku, da se na uzorku donesu zaključci koji se zatim proširuju na populaciju. Samim tim je jasno da je jako bitno da uzorak bude reprezentativan. U primenama se radi sa raznim vrstama uzoraka, a jedan od njih, istovremeno i najjednostavniji za primene je slučajan uzorak.

Prost slučajan uzorak je $n$-dimenzionalna slučajna promenljiva $\left(X_{1}, X_{2}, \ldots, X_{n}\right)$, gde su $X_{1}, X_{2}, \ldots, X_{n}$ nezavisne slučajne promenljive sa istom raspodelom. Prilikom izođenja eksperimenata beleže se dobijene (realizovane) vrednosti, tako da se $\left(x_{1}, x_{2}, \ldots, x_{n}\right)$ naziva realizovani uzorak.

\section{UNAPREĐENA METODA ZA ODREĐIVANJE EFEKTIVNE VREDNOSTI MERENE VELIČINE}

$\mathrm{Na}$ slici 1. prikazana su dva prostoperiodična napona $\mathrm{u}_{1}(\mathrm{t})$ i $\mathrm{u}_{2}(\mathrm{t})$, iste amplitude $\mathrm{i}$ učestanosti, međusobno fazno pomereni za ugao $\varphi$.

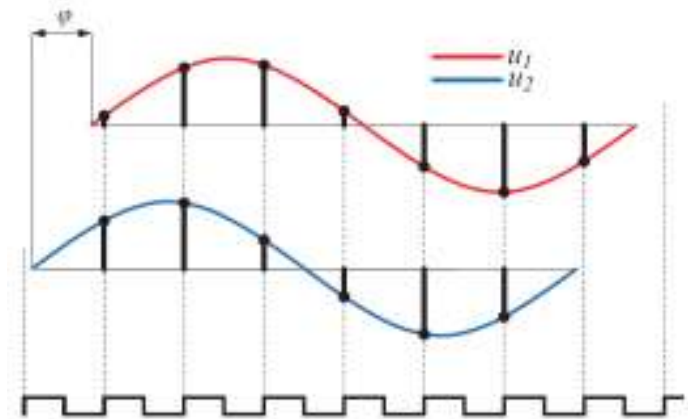

Slika 1. Ilustracija različitog broja odbiraka u okviru sinusoida istog trajanja u zavisnosti od faznog stava

Ispod je prikazana povorka impulsa čija uzlazna ivica definiše trenutke odabiranja. Iako $\mathrm{su} \mathrm{u}_{1}(\mathrm{t}) \mathrm{i} \mathrm{u}_{2}(\mathrm{t})$ iste periode, sa slike se uočava da će jedan napon biti odmeravan u šest tačaka, a drugi u sedam. Oba napona su prikazana u trajanju jedne periode, a perioda je definisana uzastopnim prolaskom rastućeg napona kroz nulti nivo.
Pokazuje se da dobijamo manju efektivnu vrednost kada je izvršeno više odabiranja u toku periode, u ovom slučaju za broj odbiraka. U jednačini (1), suma kvadrata odbiraka napona $\left(U_{i}, i=1,2, \ldots, n\right) \mathrm{u}$ brojiocu se ne promeni značajno kada se pojavi jedan odbirak više. Razlog tome jeste činjenica da je vrednost dodatnog odbirka blizu nule. $\mathrm{S}$ druge strane, deljenjem većim imeniocem dobijamo manji konačan rezultat za efektivnu vrednost.

$$
U_{\text {eff }}=\sqrt{\frac{\sum_{i=1}^{n} U_{i}^{2}}{n}}
$$

Na slici 2 prikazani su rezultati serije merenja prostoperiodičnog napona stabilne amplitude i nazivne učestanosti $50 \mathrm{~Hz}$, na osnovu odbiraka uzetih učestanošću $20 \mathrm{kHz}$.

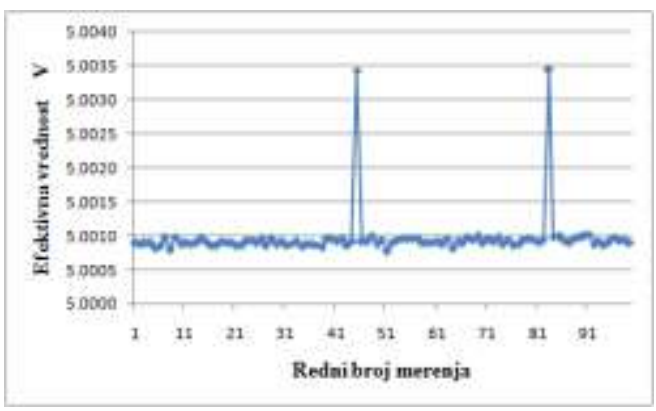

Slika 2. Rezultati serije merenja efektivne vrednosti pri nazivnoj učestanosti signala $50 \mathrm{~Hz}$ i učestanosti odmeravanja $20 \mathrm{kHz}$

Na slici 3 prikazana je druga serija merenja, pri učestanosti ulaznog napona od $50.2 \mathrm{~Hz}$. Ovde imamo zbunjujuću situaciju: uočavamo dve grupe rezultata merenja, odnosno dve tačke nagomilavanja. U okviru svake grupe, rasipanje rezultata je malo, ali su ove dve grupe prilično razmaknute. Postavlja se niz pitanja: koji su rezultati dobri, koji nisu, da li uopšte neke smemo odbaciti, koje i zašto?

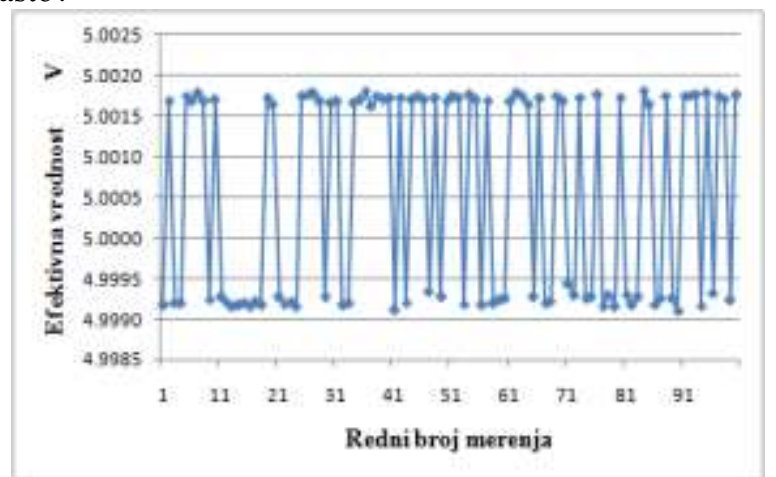

Slika 3. Rezultati serije merenja efektivne vrednosti pri nazivnoj učestanosti signala $50.2 \mathrm{~Hz}$ i $20 \mathrm{kHz}$ učestanosti odmeravanja.

Situacije na slici 2 i slici 3 odgovaraju dvema karakterističnim pojavama obrađenim u simulacijama. U prvoj situaciji imamo celobrojan odnos učestanosti $(20 \mathrm{kHz} /$ $50 \mathrm{~Hz}=400$ ). Po simulacijama bi u ovoj situaciji trebalo da dobijemo dobro grupisanje rezultata za efektivnu vrednost, pošto se svaki put dobija isti broj odbiraka $\mathrm{u}$ periodi. Dva rezultata koji primetno odstupaju su verovatno posledica odstupanja jedne ili obe učestanosti od nazivnih vrednosti, tako da njihov količnik ipak malo 
odstupa od očekivane celobrojne vrednosti.

U drugoj situaciji imamo necelobrojan odnos učestanosti $(20 \mathrm{kHz} / 50.2 \mathrm{~Hz}=398.4)$, zbog čega se u nekim slučajevima pojavi 398, a u nekim 399 odbiraka u okviru jedne periode. Iz tog razloga dobijamo i dve grupe rezultata prilikom određivanja efektivne vrednosti.

Za razliku od simulacija gde možemo da upravljamo trenutkom prvog odabiranja u okviru periode napona, $\mathrm{u}$ merenjima je ovaj trenutak slučajna pojava. Simulacije su obavljene za razne vrednosti ovog parametra. Da bismo i u merenjima dobili razne vrednosti ovog parametra (od čega zavisi konačna efektivna vrednost), između susednih merenja je napravljena kratka pauza trajanja određenog random funkcijom.

\section{EKSPERIMENT}

$\mathrm{Na}$ slici 4 prikazano je okruženje u kojem je obavljen eksperiment. Za određivanje efektivne vrednosti napona je korišćen multimetar HP3458A [3]. Multimetar je korišćen kao voltmetar za jednosmerni napon (DCV) i kao voltmetar za naizmenični napon (ACDCV). Prostoperiodičan napon stabilne efektivne vrednosti je uziman iz kalibratora TimeElectronics 5025 [4]. Radom multimetra je upravljao računar na kojem se izvršavala aplikacija napisana u programskom paketu LabView.

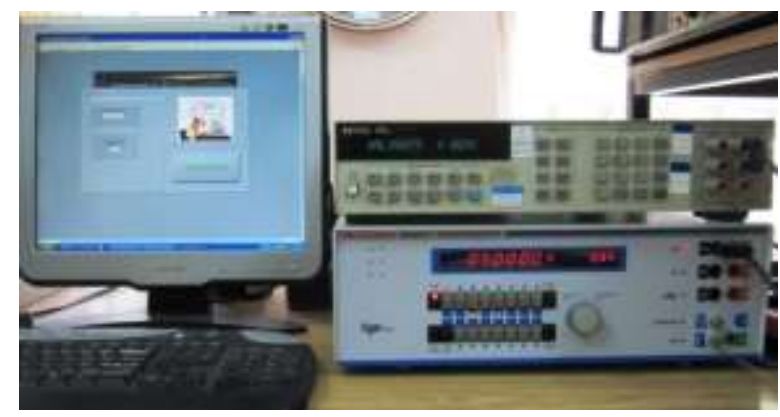

Slika 4. Uređaji korišćeni u eksperimentu

Paralelno je određivana efektivna vrednost po tri metode. Prva metoda je standardna metoda odabiranja koja određuje efektivnu vrednost na osnovu odbiraka dobijenih u okviru celog broja perioda, tako da su periode ograničene prolaskom napona kroz nulu, po (1). Ova metoda daje rezultat koji je nazvan RMSzero.

Druga metoda daje rezultat RMSrms koji se dobija takođe primenom (1), samo se ovoga puta periode definišu na osnovu prolaska rastuće ivice napona kroz prethodno određenu vrednost RMSzero. Prvo odredimo RMSzero na osnovu prolazaka kroz nulu, a onda se nad istim odbircima izvrši računanje RMSrms, ali nad periodom koja je određena prolaskom napona kroz RMSzero. Treći rezultat za efektivnu vrednost napona se dobija standardnim ACDCV postupkom ugrađenim u multimetar HP3458A. Rađene su serije od po sto merenja pri nepromenjivoj amplitudi prostoperiodičnog napona i učestanosti napona iz kalibratora.

Da bi rezultati dobijeni po tri opisane metode bili uporedivi, odlučeno je da trajanje merenja po svakoj metodi bude približno jednako. Odabrano je trajanje jedne periode mrežnog napona - 20 ms. U svakoj seriji je vršeno sto uzastopnih merenja pri nazivnoj efektivnoj vrednosti napona od $5 \mathrm{~V}$.

\section{ANALIZA REZULTATA}

U svakoj od šest serija po sto merenja je sprovedena analiza dobijenih rezultata merenja. Za svaki skup rezultata je određena srednja vrednost, standardna devijacija, minimalna i maksimalna vrednost. Na slici 5 i slici 6 su prikazane zavisnosti srednje vrednosti i standardne devijacije za sve serije i metode.

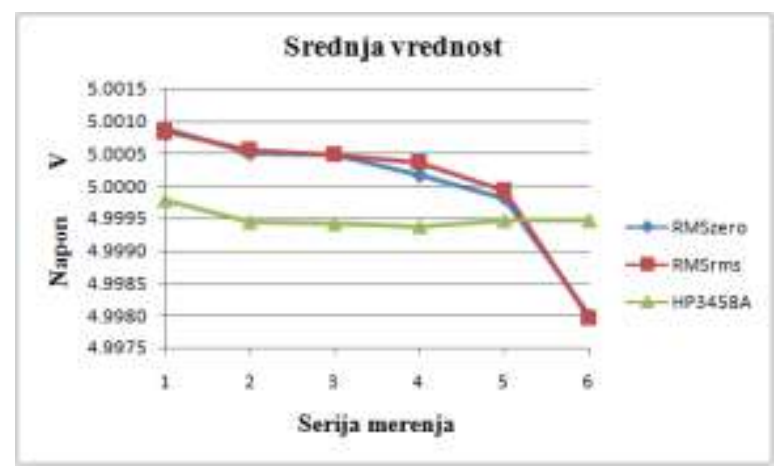

Slika 5. Zavisnost srednje vrednosti po serijama za sve tri metode

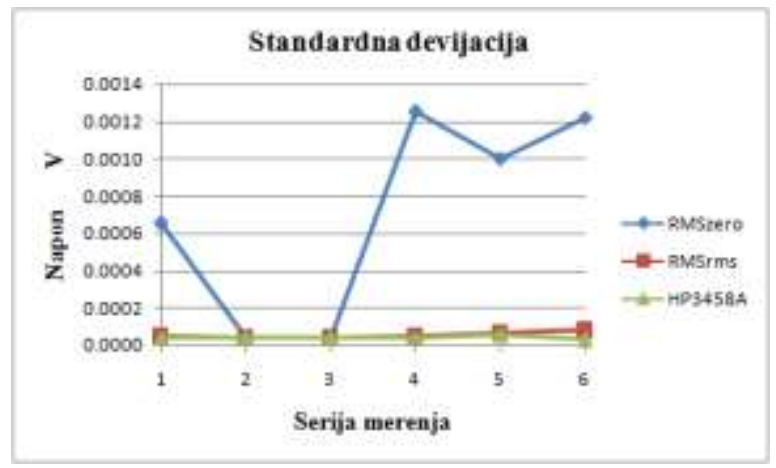

Slika 6. Zavisnost standardne devijacije po serijama za sve tri metode

Na slici 7 je prikazan opseg od minimalne do maksimalne vrednosti rezultata dobijenih po svakoj od metoda. Crnom bojom su označene granice za napon nazivne efektivne vrednosti $5 \mathrm{~V}$ po specifikaciji proizvođača kalibratora.

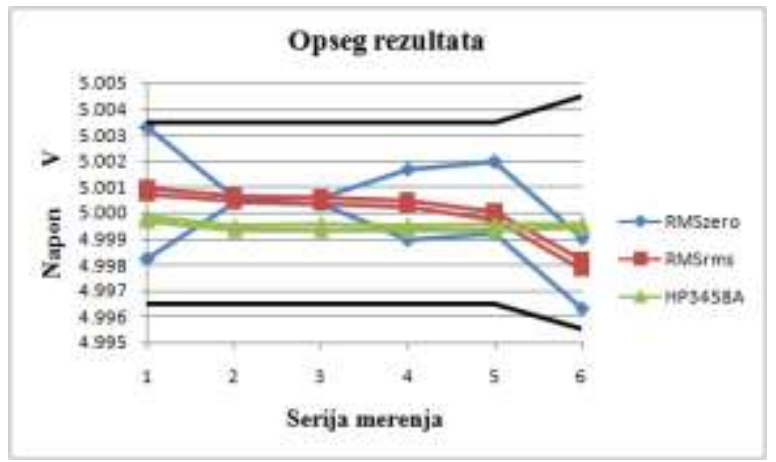

Slika 7. Opseg između minimalne i maksimalne vrednosti po serijama za sve tri metode

$\mathrm{Na}$ osnovu rezultata prikazanih na slici 5 se uočava slično ponašanje srednje vrednosti rezultata merenja po RMSzero i RMSrms metodi. Iako pojedinačni rezultati dobijeni po RMSzero metodi imaju grupisanje oko dve različite vrednosti (slika 8) zahvaljujući usrednjavanju u okviru serije (sto merenja) dobijena je srednja vrednost približno jednaka srednjoj vrednosti po unapređenoj metodi RMSrms. 


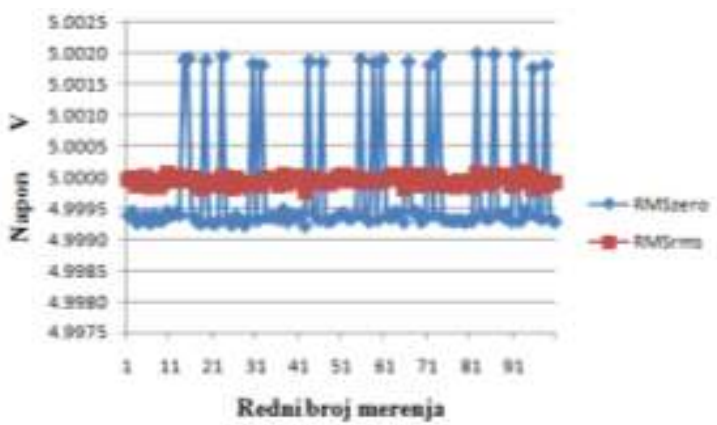

Slika 8. Rezultati RMSzero i RMSrms u okviru jedne serije merenja, pokazuju veće rasipanje rezultata RMSzero

Na slici 6 je uočljivo dobro slaganje standardne devijacije (kao mere preciznosti merenja) po metodi RMSrms i korišćenjem instrumenta HP3458A kao voltmetra za naizmenični napon, dok je rasipanje rezultata merenja po RMSzero metodi približno jednako ili uočljivo veće.

$\mathrm{Na}$ slici 7 je prikazan opseg (definisan minimalnom i maksimalnom vrednošću u svakom skupu od sto rezultata merenja) po serijama i metodama. Na ovom grafiku su docrtane crnom linijom granice u kojima bi efektivna vrednost napona iz kalibratora trebalo da se nađe, na osnovu specifikacije.

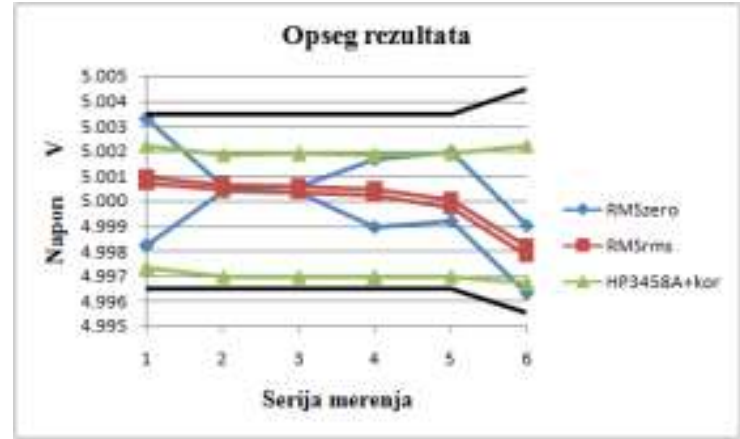

Slika 9. Opseg rezultata merenja uz uvažavanje deklarisane greške HP3458A kao naizmeničnog voltmetra

Sa slici 9 se vidi da su RMSrms rezultati uvek u okviru granica u kojima se efektivna vrednost nalazi ako verujemo instrumentu HP3458A.

\section{ZAKLJUČAK}

$\mathrm{U}$ radu su prikazani rezultati eksperimentalne provere unapređene metode za određivanje efektivne vrednosti napona. Korišćen je multimetar HP3458A, koji je za dve metode bio konfigurisan kao jednosmerni voltmetar, pri čemu je direktno korišćen AD konvertor ugrađen u instrument, dok je u trećoj metodi HP3458A korišćen kao naizmenični voltmetar. Izvršeno je poređenje dobijenih rezultata po tri metode.
Potvrđena je ispravnost unapređene metode u odnosu na standardnu metodu, a saglasnost sa referentnom metodom (HP3458A kao naizmenični voltmetar). U narednim koracima je plan da se uzme u obzir greška samog AD konvertora ugrađenog u HP3458A $\mathrm{i}$ da se procene metrološke performanse unapređene metode $\mathrm{u}$ zavisnosti od učestanosti napona, učestanosti odabiranja, amplitude napona, trajanja merenja i drugih uticajnih veličina. Pored toga, planira se da se u navedenim istraživanjima primene i savremenije matematičke metode, kao što su operatori agregacije.

\section{LITERATURA}

[1] Mladenović, P., Elementaran uvod u verovatnoću $i$ statistiku. Društvo matematičara Srbije, Beograd, 1988.

[2] Stojaković, M., Uvod u teoriju verovatnoće $i$ matematičke statistike. Novi Sad: Stylos, 1995.

[3] Anon., 1988. HP 3458A, Operating, Programming and Configuration Manual. [Online] Available at: https://xdevs.com/doc/HP_Agilent_Keysight/3458A/0 3458-90014.pdf

[4] Anon., 2012. 5025 Extended Specification, V 2.7. [Online] Available at: https://www.timeelectronics.com/assets/upload/downl oad_centre/documents/5025-extended-specs.pdf

\section{Kratka biografija:}

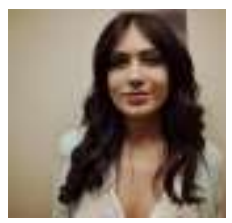

Marina Bulat rođena je u Apatinu 1988. god. Bečelor i master rad na Fakultetu tehničkih nauka iz oblasti Elektrotehnike i računarstva - Metrologija električnih veličina odbranila je 2013. godine.

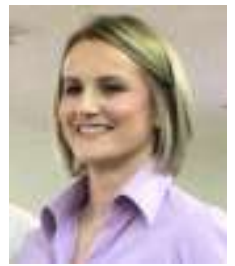

Slavica Medić rođena je 1975. godine u Novom Sadu. Doktorirala je na Fakultetu tehničkih nauka u Novom Sadu 2014. godine. Područja njenog naučnog rada su teorija verovatnoće, neaditivne mere i integrali bazirani na njima, fazi matematika i principi velikih devijacija. 